\title{
Displacements, Strains, and Tilts at Teleseismic Distances ${ }^{1}$
}

\author{
Frank Press \\ Seismological Laboratory, California Institute of Technology, Pasadena
}

\begin{abstract}
The dislocation theory representation of faulting of Vvedenskaya, Steketee, Chinnery, and Maruyama is used to compute the residual displacement, strain, and tilt fields at intermediate and large distances from major earthquakes. It is shown that the distant fields are large enough to be detected by modern instruments. The vertical displacement field from the Alaskan earthquake of March 27, 1964, indicates that the primary fault extended to a depth of 150 to $200 \mathrm{~km}$ and that it probably came to within $15 \mathrm{~km}$ of the surface. The residual strain observed at Hawaii amounted to $10^{-8}$, a value which is reasonably consistent with the extent of faulting and the displacements near the source. The elastic strain energy release was about $10^{25}$ ergs. Other observations of residual strains and tilts are examined. In some cases nonfaulting sources are probably involved. In other cases the observations may be a spurious manifestation of instrumental hysteresis. The Mindlin-Cheng catalog of fields from various nuclei of strain in a half-space offers a convenient way to derive residual displacements from diverse sources, including those of Chinnery and Maruyama.
\end{abstract}

Introduction. The residual displacement, strain, and tilt fields associated with an earthquake are diagnostic of the source mechanism, possibly even to a greater extent than are the propagating waves. The latter typically involve polarity of $P$ waves, plane of polarization of $S$ waves, spectral radiation patterns of surface waves-all of which emphasize frequencies higher than the reciprocal time duration of action at the source. Only data that include very long mantle surface waves, free oscillations, and changes in the static fields are diagnostic of the entire source region and not just the region surrounding the initial rupture. Mantle surface waves and free oscillations are excited only by the larger earthquakes. Studies of source mechanism using these waves have been initiated $[A k i$, 1964; Ben-Menahem and Toksöz, 1963; Brune, 1962] and much progress has been made. However, applications have mostly been limited to waves with insufficient length in comparison with the source dimensions. The static fields have not received much attention, particularly because data are scarce and interpretation methods are not far advanced. The vertical extent of faulting has been inferred from near displacement fields and energy decay with distance [Byerly and DeNoyer, 1958; Chinnery, 1961; Kasahara, 1957; Knopoff, 1958]. The results of

1 Contribution 1309, Division of Geological Sciences, California Institute of Technology, Pasadena. these studies have yielded surprisingly shallow depths for major faults. For example, estimates of 2 to $10 \mathrm{~km}$ were obtained for the San Andreas fault from data of the San Francisco earthquake of 1906. Theoretical residual displacements in the near field have been computed and contoured by several authors [Chinnery, 1961; Maruyama, 1964].

Strains and tilts at intermediate and teleseismic distances have been reported, but no interpretations have been offered [Benioff, 1963; Bonchkovsky, 1962].

It is my purpose in this paper to review observations of displacements, strains, and tilts at various distances, to offer some new observations, and to take a position as to their reality. The method will be to obtain these fields theoretically from a plausible fault model and to ascertain whether these fields would be detectable by existing displacement meters (primarily tide gages at this time), strain seismographs, and tiltmeters. No effort will be made to deduce source mechanism in this paper because the data are too scarce. However, if distant static fields are observable, the possibilities are many for installing appropriate instruments and monitoring seismic belts. In a sense, the distinction between dynamic and static monitoring is an artificial one, and one may view the observation and interpretation of static fields as 'zero frequency seismology.'

The fault model. Geodetic observations indi- 
cate that strain accumulation is a continuing phenomenon in seismic belts. It is natural, therefore, to associate earthquakes, at least the shallow ones, with a sudden release of strain energy accompanying an abrupt change in strength over a surface. Unfortunately, the pre-existing strain field, the mechanism of fracture, and the extent of the surface are unknown. Theory is available only for simple strain fields and elementary geometries. For these reasons, only overly idealized cases have been discussed in the literature [Knopoff, 1958; Archambeau, 1964; Press and Archambeau, 1962].

Under these circumstances, Vvedenskaya's [1956] and Steketee's [1958] representation of a fault as a displacement dislocation surface in an elastic half-space has much merit, particularly if our interest is in computing the displacement, strain, and tilt fields at locations removed from the fault zone. The basic assumption in this procedure is that the displacements following an earthquake can be modeled by the corresponding fields of a dislocation sheet with displacement discontinuity matching the observed slip. Chinnery [1961, 1963] used Steketee's results in calculating the displacement and stress field in the vicinity of a vertical, rectangular, strikeslip fault. Maruyama [1964] made some formal extensions of Steketee's work and calculated the near displacement field for a vertical rectangular dip-slip fault. Maruyama summarizes the earlier work of Sezawa, Whipple, Soeda, and Yamakawa, who used various forms of internal strain nuclei to represent earthquake sources.

Steketee showed that the displacement field $u_{k}$ corresponding to a displacement dislocation $U_{1}$ across a dislocation surface $\Sigma$ is given by

$$
u_{k}=\frac{1}{8 \pi \mu} \iint_{\Sigma} U_{i} \omega_{i}{ }^{k} \alpha_{i} d \Sigma
$$

Here $a_{j}$ are the direction cosines of the normal to the surface element $d \Sigma$ and $\mu$ is the rigidity.

The $\omega_{i j}{ }^{k}$ are obtainable from the displacements corresponding to nuclei of strain in a half-space (equation 5). Steketee showed a method of obtaining the six $\omega_{i j}{ }^{k}$ fields by using a Green's function and derived $\omega_{12}{ }^{k}$, which are pertinent to a vertical strike-slip fault. Maruyama derived the remaining five functions. Although both authors took advantage of a condensed formulation made possible by the use of the Galerkin vector strain function, the derivations are rather lengthy.

The appropriate value for $\omega_{4 j}{ }^{k}$ can be derived in a straightforward manner by using results by Mindlin and Cheng [1950], who gave explicit expressions for the displacement and stress fields for half-space nuclei of strain consisting of single forces and double forces with and without moment. It is only necessary to write the single force results since the other forms can be obtained by taking appropriate derivatives. These results for the half-space make possible the solution of many problems in terms of combinations of strain nuclei in the same way that the classical results for nuclei in solids of unlimited extent have been used.

The half-space occupies the region $x_{3}>0$. Point nuclei are at $\xi_{1}, 0, \xi_{8}$.

$$
\begin{aligned}
& R^{2}=\left(x_{1}-\xi_{1}\right)^{2}+{x_{2}}^{2}+\left(x_{3}-\xi_{3}\right)^{2} \\
& Q^{2}=\left(x_{1}-\xi_{1}\right)^{2}+{x_{2}}^{2}+\left(x_{3}+\xi_{3}\right)^{2}
\end{aligned}
$$

$\lambda, \mu$ are Lamé's constants and $v$ is Poisson's ratio.

For a single force in $x_{1}$ direction with magnitude $8 \pi \mu(\lambda+2 \mu) /(\lambda+\mu)$,

$$
\begin{aligned}
u_{1}{ }^{1}= & \frac{3-4 \nu}{R}+\frac{1}{Q} \\
& +\frac{2 \xi_{3} x_{3}}{Q^{3}}+\frac{4(1-\nu)(1-2 \nu)}{Q+x_{3}+\xi_{3}} \\
& +\left(x_{1}-\xi_{1}\right)^{2}\left[\frac{1}{R^{3}}+\frac{3-4 \nu}{Q^{3}}\right. \\
& \left.-\frac{6 \xi_{3} x_{3}}{Q^{5}}-\frac{4(1-\nu)(1-2 \nu)}{Q\left(Q+x_{3}+\xi_{3}\right)^{2}}\right]
\end{aligned}
$$

$$
\begin{aligned}
u_{2}{ }^{1}= & \left(x_{1}-\xi_{1}\right) x_{2}\left[\frac{1}{R^{3}}+\frac{3-4 \nu}{Q^{3}}\right. \\
& \left.-\frac{6 \xi_{3} x_{3}}{Q^{5}}-\frac{4(1-\nu)(1-2 \nu)}{Q\left(Q+x_{3}+\xi_{3}\right)^{2}}\right]
\end{aligned}
$$

and

$$
\begin{gathered}
u_{3}{ }^{1}=\left(x_{1}-\xi_{1}\right)\left[\frac{x_{3}-\xi_{3}}{R^{3}}+\frac{(3-4 \nu)\left(x_{3}-\xi_{3}\right)}{Q^{3}}\right. \\
\left.-\frac{6 \xi_{3} x_{3}\left(x_{3}+\xi_{3}\right)}{Q^{5}}+\frac{4(1-\nu)(1-2 \nu)}{Q\left(Q+x_{3}+\xi_{3}\right)}\right]
\end{gathered}
$$

For a single force in $x_{2}$ direction with magnitude $8 \pi \mu(\lambda+2 \mu) /(\lambda+\mu)$, 


$$
\begin{aligned}
u_{1}^{2}= & \left(x_{1}-\xi_{1}\right) x_{2}\left[\frac{1}{R^{3}}+\frac{3-4 \nu}{Q^{3}}\right. \\
& \left.-\frac{6 \xi_{3} x_{3}}{Q^{5}}-\frac{4(1-\nu)(1-2 \nu)}{Q\left(Q+x_{3}+\xi_{3}\right)^{2}}\right] \\
u_{2}^{2}= & \frac{3-4 \nu}{R}+\frac{1}{Q} \\
& +\frac{2 \xi_{3} x_{3}}{Q^{3}}+\frac{4(1-\nu)(1-2 \nu)}{\left(Q+x_{3}+\xi_{3}\right)} \\
& +x_{2}^{2}\left[\frac{1}{R^{3}}+\frac{3-4 \nu}{Q^{3}}\right. \\
& \left.-\frac{6 \xi_{3} x_{3}}{Q^{5}}-\frac{4(1-\nu)(1-2 \nu)}{Q\left(Q+x_{3}+\xi_{3}\right)^{2}}\right]
\end{aligned}
$$

and

$$
\begin{gathered}
u_{3}^{2}=x_{2}\left[\frac{x_{3}-\xi_{3}}{R^{3}}+\frac{(3-4 \nu)\left(x_{3}-\xi_{3}\right)}{Q^{3}}\right. \\
\left.-\frac{6 \xi_{3} x_{3}\left(x_{3}+\xi_{3}\right)}{Q^{5}}+\frac{4(1-\nu)(1-2 \nu)}{Q\left(Q+x_{3}+\xi_{3}\right)}\right]
\end{gathered}
$$

For a single force in $x_{3}$ direction with magnitude $8 \pi \mu(\lambda+2 \mu) /(\lambda+\mu)$,

$$
\begin{gathered}
u_{1}{ }^{3}=\left(x_{1}-\xi_{1}\right)\left[\frac{x_{3}-\xi_{3}}{R^{3}}+\frac{(3-4 \nu)\left(x_{3}-\xi_{3}\right)}{Q^{3}}\right. \\
\left.+\frac{6 \xi_{3} x_{3}\left(x_{3}+\xi_{3}\right)}{Q^{5}}-\frac{4(1-\nu)(1-2 \nu)}{Q\left(Q+x_{3}+\xi_{3}\right)}\right] \\
u_{2}{ }^{3}=x_{2}\left[\frac{x_{3}-\xi_{3}}{R^{3}}+\frac{(3-4 \nu)\left(x_{3}-\xi_{3}\right)}{Q^{3}}\right. \\
\left.+\frac{6 \xi_{3} x_{3}\left(x_{3}+\xi_{3}\right)}{Q^{5}}-\frac{4(1-\nu)(1-2 \nu)}{Q\left(Q+x_{3}+\xi_{3}\right)}\right]
\end{gathered}
$$

and

$$
\begin{aligned}
& u_{3}{ }^{3}=\frac{3-4 \nu}{R} \\
& +\frac{8(1-\nu)^{2}-(3-4 \nu)}{Q}+\frac{\left(x_{3}-\xi_{3}\right)^{2}}{R^{3}} \\
& +\frac{(3-4 \nu)\left(x_{3}+\xi_{3}\right)^{2}-2 \xi_{3} x_{3}}{Q^{3}} \\
& +\frac{6 \xi_{3} x_{3}\left(x_{3}+\xi_{3}\right)^{2}}{Q^{5}}
\end{aligned}
$$

Noting that (1) assumes force nuclei of magnitude $8 \pi \mu$ and taking into account that $x_{j}$ and $\xi_{3}$ are interchanged in Mindlin vis-a-vis Steketee, we can show that

$$
\begin{aligned}
\omega_{\imath j}{ }^{k}=\frac{\lambda+\mu}{\lambda+2 \mu}\left[\lambda \delta_{\imath j} \frac{\partial u_{k}{ }^{2}}{\partial \xi_{l}}\right. & \\
& \left.+\mu\left(\frac{\partial u_{k}{ }^{i}}{\partial \xi_{i}}+\frac{\partial u_{k}{ }^{2}}{\partial \xi_{\imath}}\right)\right]
\end{aligned}
$$

When $i=j$, the $\partial u_{k} l / \partial \xi_{l}$ (summed over $1=1$, $2,3)$ correspond to displacements from a center of dilatation and the $\partial u_{k}^{i} / \partial \xi_{i}$ correspond to double forces without moment. For $i \neq j$, the $\left(\partial u_{k}{ }^{i} / \partial \xi_{i}+\partial u_{k}^{i} / \partial \xi_{i}\right)$ are displacements from two coplanar, mutually perpendicular double forces, each with moment. These force systems are shown schematically in Figure 1.

In this discussion we are interested in vertical strike-slip and dip-slip faults. If the fault is in the plane $\xi_{2}=0$ and extends horizontally and vertically over the ranges $-L \leq \xi_{1} \leq L$ and $d \leq \xi_{3} \leq D$, respectively, for strike-slip equation 1 takes the form

$$
\begin{aligned}
u_{k}=\frac{(\lambda+\mu) U_{1}}{8 \pi(\lambda+2 \mu)} \\
\quad \cdot \int_{d}^{D} \int_{-L}^{L}\left(\frac{\partial u_{k}{ }^{1}}{\partial \xi_{2}}+\frac{\partial u_{k}{ }^{2}}{\partial \xi_{1}}\right) d \xi_{1} d \xi_{3}
\end{aligned}
$$

and for dip-slip it is

$$
\begin{aligned}
u_{k}=\frac{(\lambda+\mu) U_{3}}{8 \pi(\lambda+2 \mu)} \\
\quad \cdot \int_{d}^{D} \int_{-L}^{L}\left(\frac{\partial u_{k}{ }^{3}}{\partial \xi_{2}}+\frac{\partial u_{k}{ }^{2}}{\partial \xi_{3}}\right) d \xi_{1} d \xi_{3}
\end{aligned}
$$

where $U_{1}$ and $U_{\mathrm{s}}$ are the horizontal and vertical displacement dislocations across the fault. After somewhat lengthy evaluations and with the assumption $\lambda=\mu$, these integrations can be reduced to the following expressions for displacements, horizontal strains, and tilts at the free surface $\left(x_{1}, x_{2}, 0\right)$ where $R=Q$. We use Chinnery's notation || to represent the substitution $f\left(\xi_{1}, \xi_{s}\right) \|=f(L, D)-f(L, d)-f(-L, D)$ $+f(-L, d)$.

the displacements are

\section{For strike-slip}

$$
\begin{aligned}
u_{1}=\frac{U_{1}}{8 \pi}\{- & \frac{x_{2}\left(x_{1}-\xi_{1}\right)\left(3 R+4 \xi_{3}\right)}{R\left(R+\xi_{3}\right)^{2}} \\
& \left.+4 \tan ^{-1} \frac{x_{2} R}{\xi_{3}\left(x_{1}-\xi_{1}\right)}\right\}
\end{aligned}
$$


2398

$u_{2}=\frac{U_{1}}{8 \pi}\left\{\ln \left(R+\xi_{3}\right)+\frac{\xi_{3}}{R+\xi_{3}}\right.$

$$
\left.--\frac{x_{2}{ }^{2}\left(3 R+4 \xi_{3}\right)}{R\left(R+\xi_{3}\right)^{2}}\right\} \mid
$$

$u_{3}=\frac{U_{1}}{4 \pi}\left\{\frac{x_{2}\left(R+2 \xi_{3}\right)}{R\left(R+\xi_{3}\right)}\right\} \mid$

the strains are
FRANK PRESS

$$
\frac{\partial u_{1}}{\partial x_{1}}=-\frac{U_{3}}{2 \pi}\left[\frac{x_{2}\left(x_{1}-\xi_{1}\right)}{R^{3}}\right] \|
$$

(8) $\frac{\partial u_{1}}{\partial x_{2}}=\frac{U_{3}}{2 \pi}\left[\frac{R^{2}-x_{2}{ }^{2}}{R^{3}}\right] \mid$

$$
\frac{\partial u_{2}}{\partial x_{1}}=-\frac{U_{3}}{2 \pi}\left[\frac{x_{2}{ }^{2}}{R^{3}}\right] \|
$$

$$
\begin{aligned}
& \frac{\partial u_{1}}{\partial x_{1}}=\frac{U_{1}}{8 \pi}\left\langle\frac{x_{2}}{\left(R+\xi_{3}\right)^{2}}\left\{1-\frac{\left(x_{1}-\xi_{1}\right)^{2}\left[3 R\left(R+\xi_{3}\right)-\left(3 R+4 \xi_{3}\right)\left(3 R+\xi_{3}\right)\right]}{R^{3}\left(R+\xi_{3}\right)}\right\}\right\rangle \| \\
& \frac{\partial u_{1}}{\partial x_{2}}=\frac{U_{1}}{8 \pi}\left\langle\frac{\left(x_{1}-\xi_{1}\right)}{R}\left\{\frac{4 \xi_{3}}{x_{2}{ }^{2}+\xi_{3}{ }^{2}}-\frac{7 R+8 \xi_{3}}{\left(R+\xi_{3}\right)^{2}}-\frac{x_{2}{ }^{2}\left[3 R\left(R+\xi_{3}\right)-\left(3 R+4 \xi_{3}\right)\left(3 R+\xi_{3}\right)\right]}{R^{2}\left(R+\xi_{3}\right)^{3}}\right\}\right\rangle \| \\
& \frac{\partial u_{2}}{\partial x_{1}}=\frac{U_{1}}{8 \pi}\left\langle\frac{\left(x_{1}-\xi_{1}\right)}{\left(R+\xi_{3}\right)^{2}}\left\{1-\frac{x_{2}{ }^{2}\left[3 R\left(R+\xi_{3}\right)-\left(3 R+4 \xi_{2}\right)\left(3 R+\xi_{3}\right)\right]}{R^{3}\left(R+\xi_{3}\right)}\right\}\right\rangle \mid \| \\
& \frac{\partial u_{2}}{\partial x_{2}}=\frac{U_{1}}{8 \pi}\left\langle\frac{x_{2}}{\left(R+\xi_{3}\right)^{2}}\left\{1-\frac{2\left(3 R+4 \xi_{3}\right)}{R}-\frac{x_{2}{ }^{2}\left[3 R\left(R+\xi_{3}\right)-\left(3 R+4 \xi_{3}\right)\left(3 R+\xi_{3}\right)\right]}{R^{3}\left(R+\xi_{3}\right)}\right\}\right\rangle \|
\end{aligned}
$$

and the tilts are

$$
\begin{aligned}
& \frac{\partial u_{3}}{\partial x_{1}}=\frac{U_{\mathrm{I}}}{4 \pi}\left\{\frac{x_{2}\left(x_{1}-\xi_{1}\right)\left[R\left(R+\xi_{3}\right)-\left(R+2 \xi_{3}\right)\left(2 R+\xi_{3}\right)\right]}{R^{3}\left(R+\xi_{3}\right)^{2}}\right\} \mid \\
& \frac{\partial u_{3}}{\partial x_{2}}=\frac{U_{1}}{4 \pi}\left\{\frac{x_{2}{ }^{2}\left[R\left(R+\xi_{3}\right)-(R+2 \xi)\left(2 R+\xi_{9}\right)\right]}{R^{3}\left(R+\xi_{3}\right)^{2}}+\frac{R+2 \xi_{3}}{R\left(R+\xi_{3}\right)}\right\} \mid
\end{aligned}
$$

the displacements are

\section{For dip-slip}

$$
\begin{aligned}
& u_{1}=\frac{U_{3}}{2 \pi}\left[\frac{x_{2}}{R}\right] \| \\
& u_{2}=-\frac{U_{3}}{2 \pi}\left[\frac{x_{2}{ }^{2}\left(x_{1}-\xi_{1}\right)}{R\left(x_{2}{ }^{2}+\xi_{3}{ }^{2}\right)}\right] \| \\
& u_{3}=\frac{U_{3}}{2 \pi}\left[\frac{x_{2} \xi_{3}\left(x_{1}-\xi_{1}\right)}{R\left(x_{2}{ }^{2}+\xi_{3}{ }^{2}\right)}\right.
\end{aligned}
$$$$
\left.+\tan ^{-1} \frac{x_{2} R}{\xi_{3}\left(x_{1}-\xi_{1}\right)}\right] \mid
$$

$$
\cdot\left[\frac{x_{9}\left(x_{1}-\xi_{1}\right)\left(2 R^{2} \xi_{3}{ }^{2}-x_{2}{ }^{2} \xi_{3}{ }^{2}-x_{2}{ }^{4}\right)}{R^{3}\left(x_{2}{ }^{2}+\xi_{3}{ }^{2}\right)^{2}}\right] \mid
$$

and the tilts are

$$
\begin{gathered}
\frac{\partial u_{3}}{\partial x_{1}}=\frac{U_{3}}{2 \pi}\left\{\frac { x _ { 2 } \xi _ { 3 } } { R } \left[\frac{1}{R^{2}}\right.\right. \\
\left.\left.\quad-\frac{1}{\left(x_{1}-\xi_{1}\right)^{2}+x_{2}{ }^{2}}\right]\right\} \mid \\
\frac{\partial u_{3}}{\partial x_{2}}=\frac{U_{3}}{2 \pi}\left\{\frac{\left(x_{1}-\xi_{1}\right) \xi_{3}}{\left(x_{2}{ }^{2}+\xi_{3}{ }^{2}\right)}\right. \\
\cdot\left[\frac{\xi_{3}{ }^{2}-x_{2}{ }^{2}}{R\left(x_{2}{ }^{2}+\xi_{3}{ }^{2}\right)}+\frac{\left(x_{1}-\xi_{1}\right)^{2}+\xi_{3}{ }^{2}}{R^{3}}\right. \\
\left.\left.+\frac{x_{2}{ }^{2}+\xi_{3}{ }^{2}}{R\left[\left(x_{1}-\xi_{1}\right)^{2}+x_{2}{ }^{2}\right]}\right]\right\} \|
\end{gathered}
$$



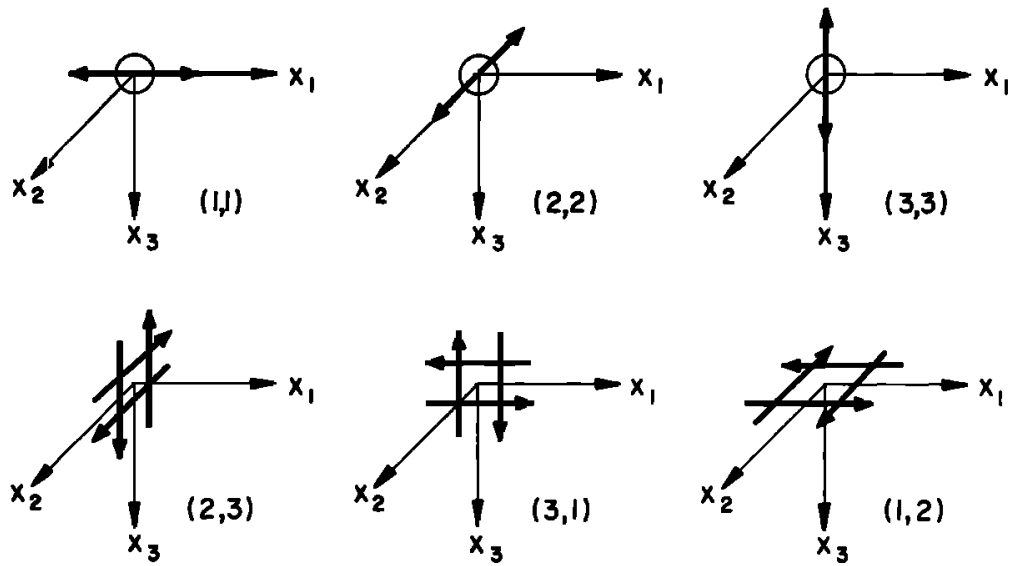

Fig. 1. Representation of force systems corresponding to $\omega_{i, j}$.

The displacements for strike-slip faults are the same as those given by Chinnery [1961]. The displacements for dip-slip faults correspond to those given by Maruyama [1964]. These investigators also presented numerical results for the near displacement field $x_{1}, x_{2} \sim 2 L$ for $d=0$ and several values of $D$. In this paper we are mostly concerned with the distant field $x_{1}$, $x_{2} \sim 10 L$ for displacements, strains, and tilts.

The fields at teleseismic distances. Equations 8 to 13 have been programmed for automatically contoured output from an IBM 7094 computer. Results are given in Figures 2 to 10 for the two cases of $D=0.1 L$ and $D=1.0 L$ with $d=0$. The map scale is in units of half-fault length. Dimensionless displacements $u_{k} / U_{1}$ or $u_{k} / U_{3}$ are plotted. The strain and tilt results assume slip values $U_{1}$ or $U_{3}$ of $1 / 3 \times 10^{-4} \mathrm{~L}$. This corresponds to a 10-meter displacement for a fault with a total length of $600 \mathrm{~km}$. Since strains and tilts are proportional to $U_{k}$ the results can readily be transformed to correspond to any particular situation.

Several features of special interest emerge from these figures. Since modern instruments can detect residual strain and tilt changes in the range $10^{-9}$ to $10^{-8}$ under typical noise conditions, we see that when such changes accompany major earthquakes they are observable to distances of the order of several thousand kilometers. Displacements as large as a half-centimeter occur at these distances. Whether these surprisingly large residual displacements are detectable is questionable. Sea level changes of this magnitude are readily measurable, but the permanent offsets must be detected in the presence of waves, tides, seasonal changes, and local eustatic changes. Detection of residual displacements by pendulum seismographs would require multiple integration of trace motion in the presence of even larger transient waves, a difficult task which was recently attempted by Berckhemer and Schneider [1964].

Observations of displacements, strains, and tilts. A number of investigators have reported residual strains and tilts at large distances from earthquakes. Benioff [1963] displayed a strain seismogram with a residual offset following the Montana shock of August 18, 1959 (magnitude 7.2 , distance $1200 \mathrm{~km}$ ). Bonchkovsky [1962], Nishimura [1953], and Tomaschek [1955] reported tilts at large distances from major earthquakes. There is some question concerning the reality of these observations. The instruments are extremely sensitive and it is not impossible that they will undergo a permanent mechanical or electrical offset following the large impulses delivered by the transient waves. In what follows, I will attempt to make a case that the strain observations probably represent real deformation in the ground and that the tilts could be spurious. The procedure of comparing the observed values of strains and tilts with values expected from the fault model described earlier is followed, and local field evidence is used to estimate the source parameters of fault length, vertical extent, and slip. Preliminary results from a new photo-optical transducer on the 

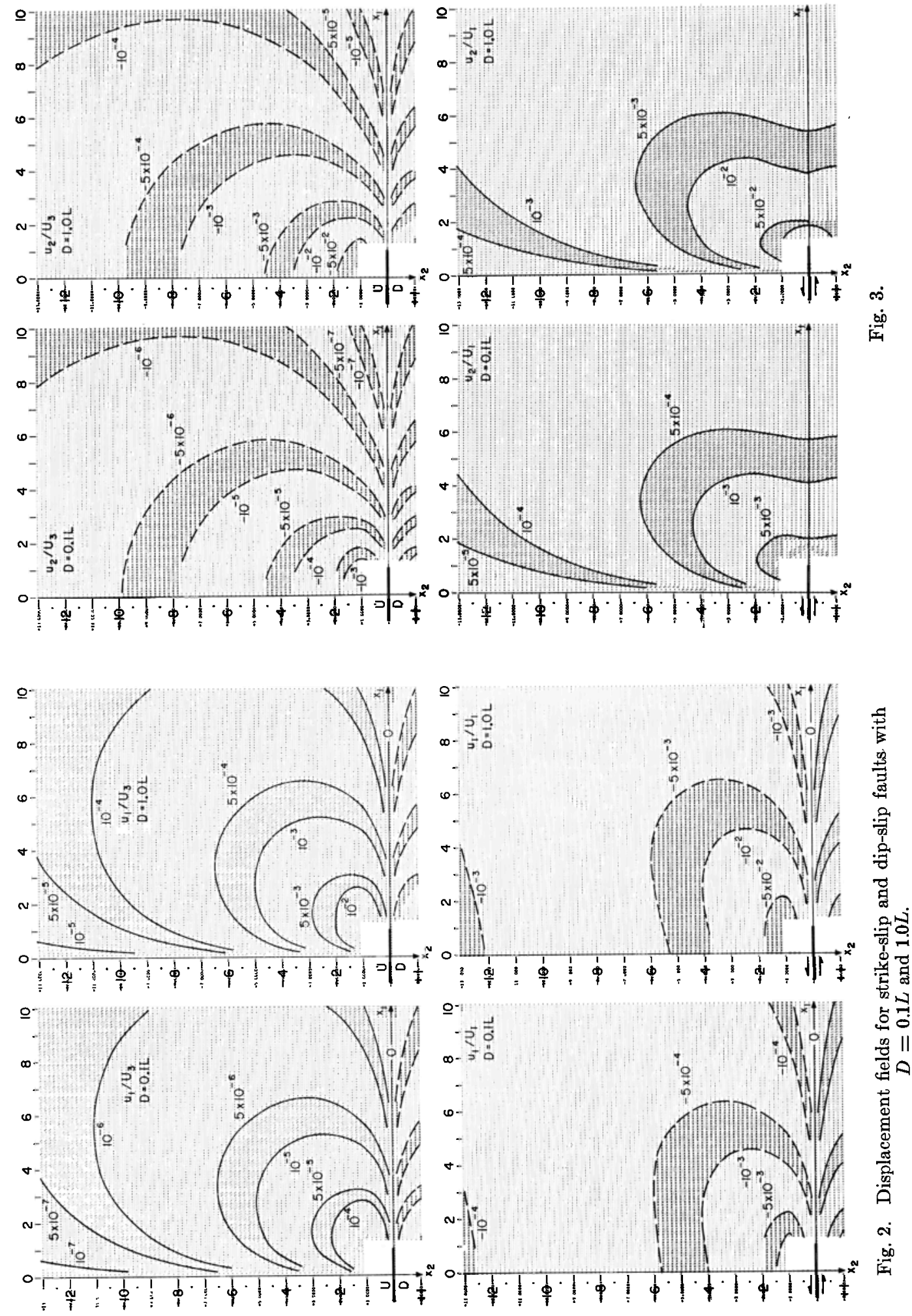

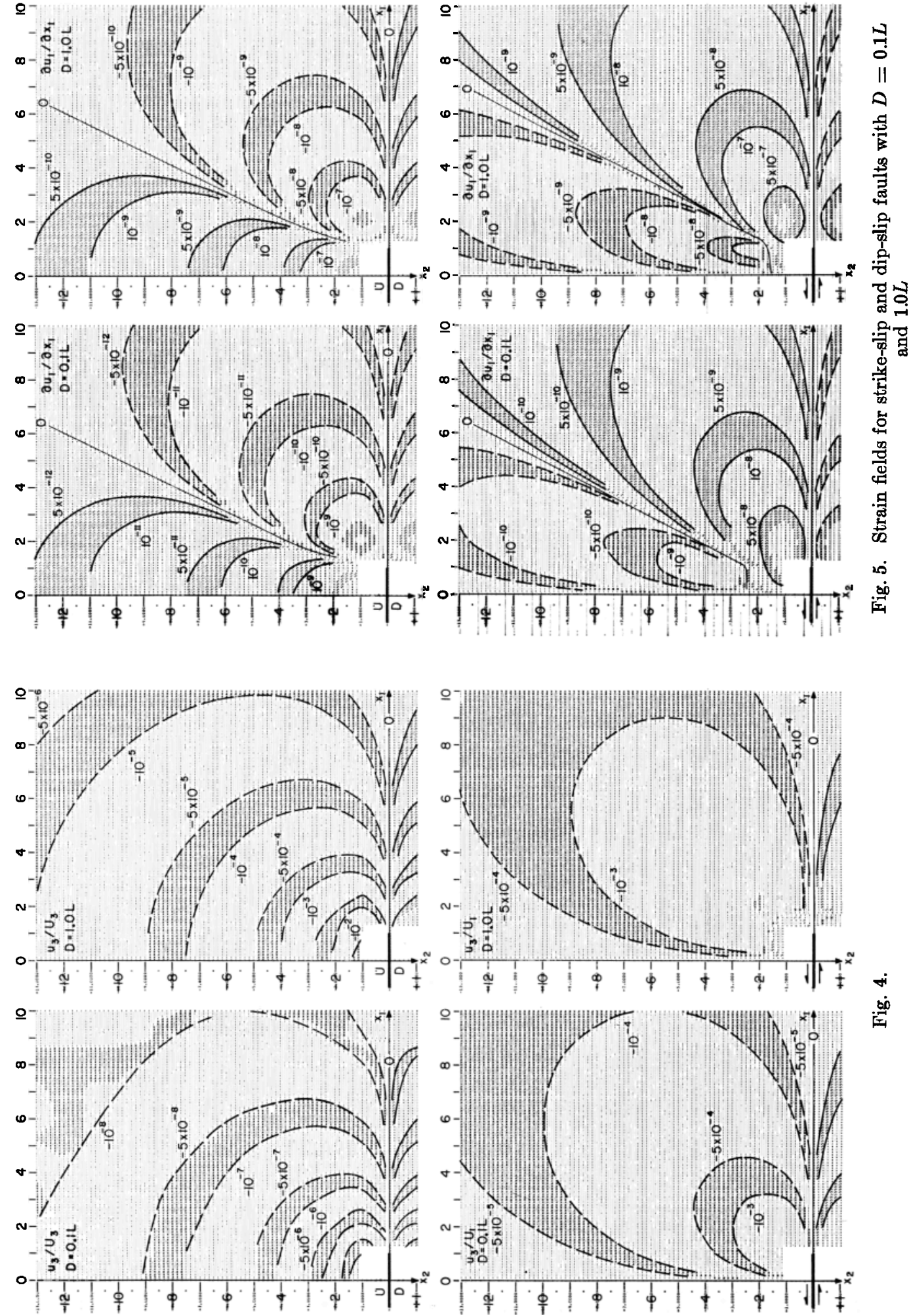

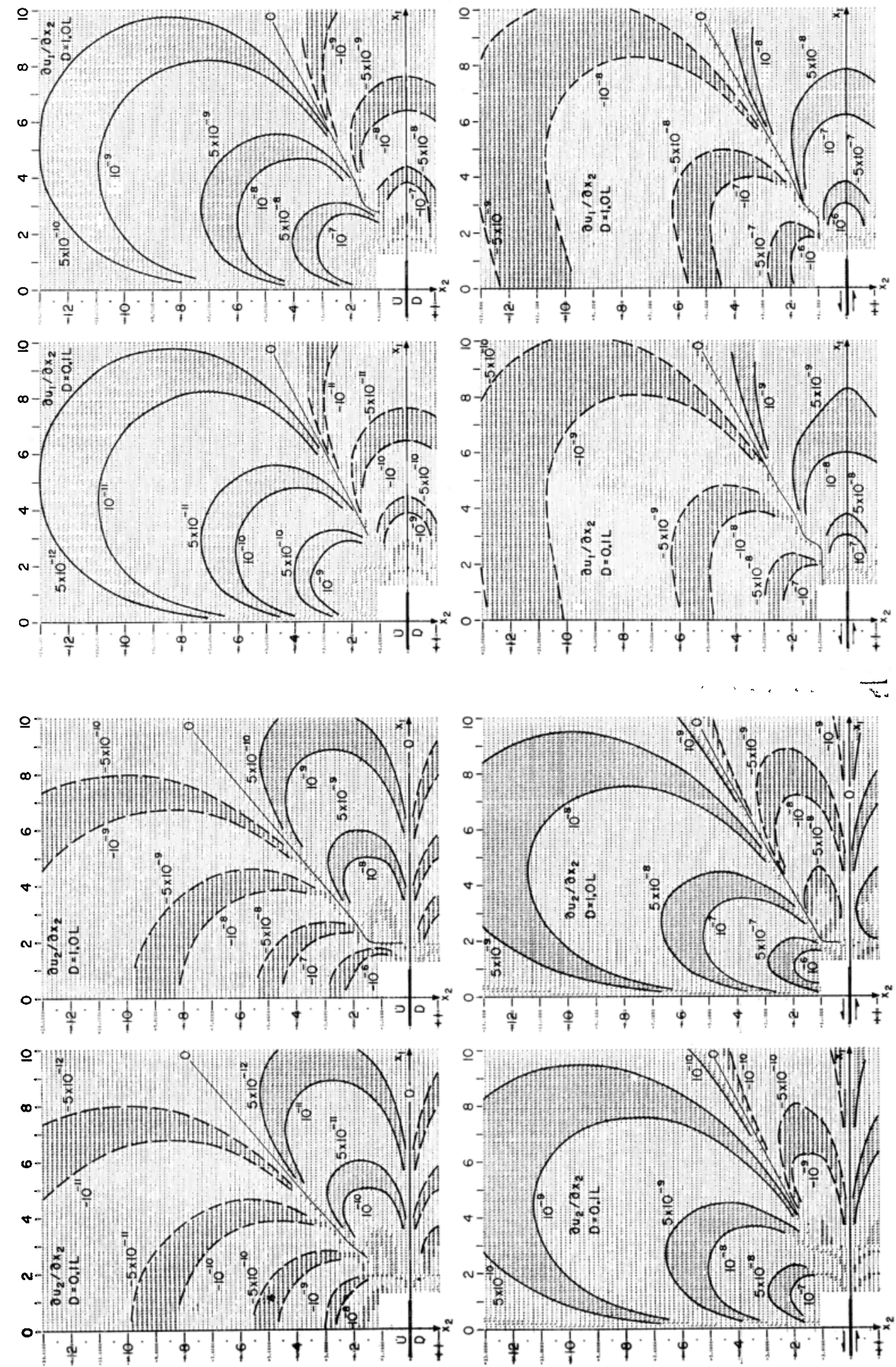

ن 
DISPLACEMENTS, STRAINS, AND TILTS
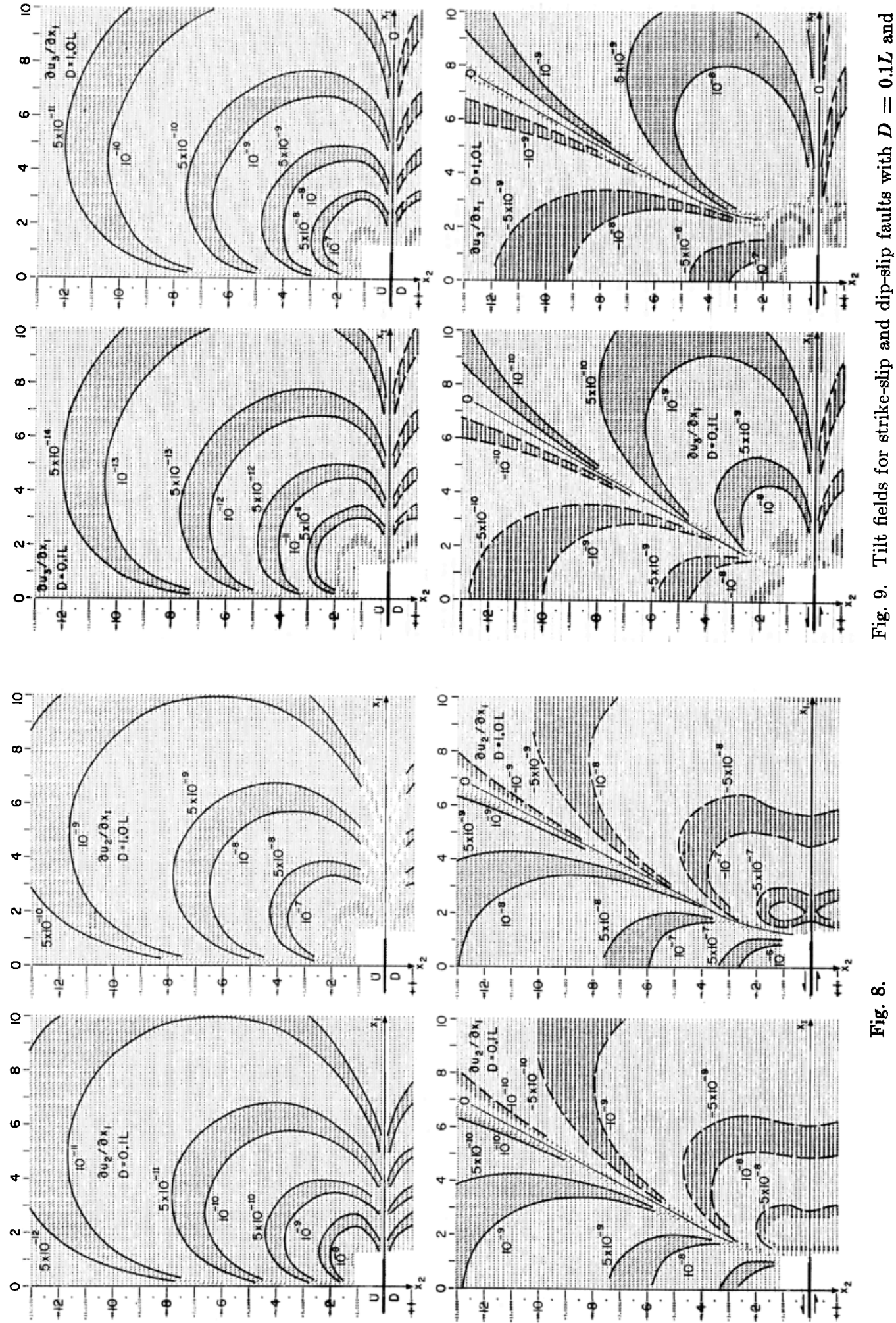

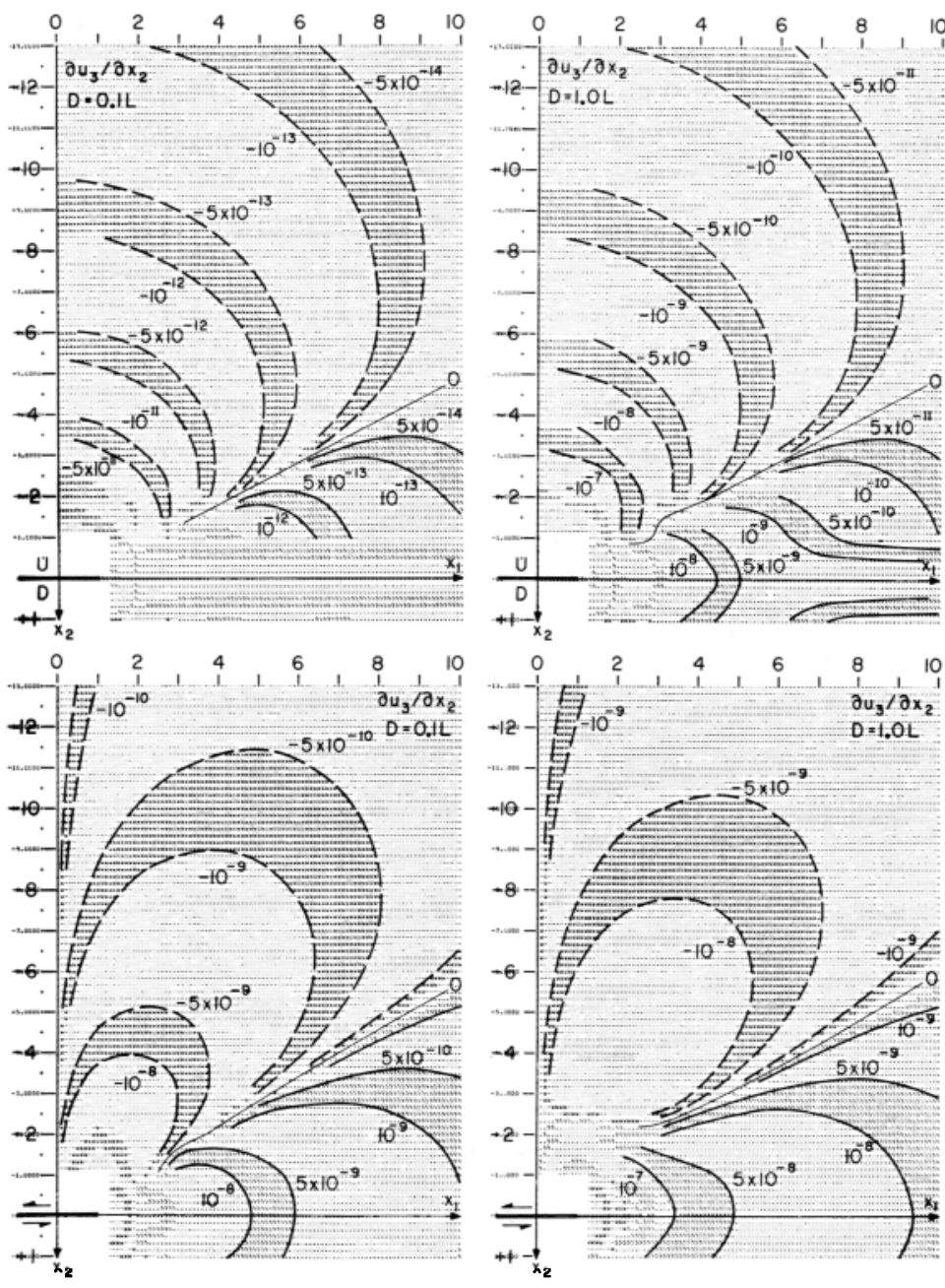

Fig. 10.

strain seismograph, designed by Blayney and Gilman [1965], are used to support the case.

The Alaskan earthquake of March 27, 1964. This great earthquake with Richter magnitude of 8.4 to 8.6 had epicentral coordinates $61.1^{\circ} \mathrm{N}$ and $147.4^{\circ} \mathrm{W}$ and a focal depth of about $50 \mathrm{~km}$. More than 7500 aftershocks were instrumentally detected, defining a belt $800 \mathrm{~km}$ long and 250 $\mathrm{km}$ wide, azimuth $42^{\circ}$. The length of the belt is somewhat larger than the fault length of 650 $\mathrm{km}$ determined instrumentally using the directivity function (A. Ben-Menahem and $M$. N. Toksöz, personal communication, December 20, 1964). Average focal depths for some 200 aftershocks for which determinations were made was $20 \mathrm{~km}$, the deepest event occurring at $60 \mathrm{~km}$.
One fault plane solution for the main shock and aftershocks indicates dips of about $80^{\circ} \mathrm{E}$ and the azimuth of the strike is about $60^{\circ}$. [Algermissen, 1964]. Preliminary fault plane solutions from surface waves establish this as the unique solution (A. Ben-Menahem and M. N. Toksöz, personal communication, December 20, 1964). A special array of sensitive seismographs was installed by K. Aki after the earthquake. He was able to locate hundreds of aftershocks in a few weeks time, some of which occurred at depths as great as $200 \mathrm{~km}$ (Aki, personal communication, December 15, 1964).

Tectonic uplift and subsidence for this earthquake are comparatively well documented over large distances because permanent sea level 
changes along an irregular and lengthy coastline were evidenced in tide gage and shoreline data. The uplifted block extends southeast from the epicentral belt, its area exceeding $75,000 \mathrm{~km}^{2}$. Most shorelines in this zone rose several feet. Montague Island lies in the zone of greatest tectonic activity. Local faults showing dominantly vertical slips as much as $5 \mathrm{~m}$ have been reported. A small part of the island rose more than $10 \mathrm{~m}$ and most of it rose 3 to $6 \mathrm{~m}$ [Plafker, 1965; Grantz et al., 1964a, b]. Similarly the sea bottom southwest of Montague Island was predominantly uplifted 3 to $6 \mathrm{~m}$, although very localized zones showed changes of more than 15 m [Malloy, 1964].

Available data for the down-dropped block to the northwest compiled by these investigators indicate that it exceeded $75,000 \mathrm{~km}^{2}$ in area and sank as much as $2 \mathrm{~m}$. The vertical movements do not imply a primary fault extending to the surface, but rather a zone of flexure between the uplifted and down-dropped blocks some 100 to $120 \mathrm{~km}$ wide, which to the precision of the data lies within the belt of epicenters of aftershocks. A plot of vertical movement projected on a section normal to the tectonic belt is shown in Figure 11. We consider the surface faulting and the local zones of intense uplift on Montague Island to be secondary features associated with the region of greatest flexure.

Preliminary results from geodetic resurveying show left lateral horizontal movement between Montague and Latouche islands amounting to 5 to $6 \mathrm{~m}$ [Whitten, 1964].
We use the following procedure to deduce the extent of the fault and the values for slip. We take the length of the fault $2 L=800 \mathrm{~km}$ to be that given by the length of the epicentral belt. No significant change in our conclusions would occur had we used the length of $650 \mathrm{~km}$ indicated in the directivity function analysis. The distribution of vertical movements, the fault plane solutions from body and surface waves, and the distribution of focal depths imply a near-vertical plane for the primary fault. The occurrence of a zone of flexure rather than a primary scarp suggests that the upper boundary of the primary fault did not reach the surface. We shall deduce the vertical extent of faulting by assuming a vertical fault plane and using the observed movements and theory described earlier. This is the method of Kasahara [1957] and Chinnery [1961] among others. The vertical slip $U_{\mathrm{s}} \leq 20 \mathrm{~m}$ since this is the difference between the maximum uplift and subsidence. If one weights the vertical movements in the zone of most intense deformation according to the area over which they occur, then 6 to $9 \mathrm{~m}$ is a more likely average value for $U_{3}$.

Two types of theoretical displacement curves, based on equation 11, are drawn through the data in Figure 11. The curves with $d=0$ show the expected scarp when the fault breaks the surface. The curves with $d=0.04 L \sim 16 \mathrm{~km}$ show a zone of flexure with zero displacement above the fault. The two curves are indistinguishable outside the zone of flexure, i.e. at distances greater than about $30 \mathrm{~km}$ normal to

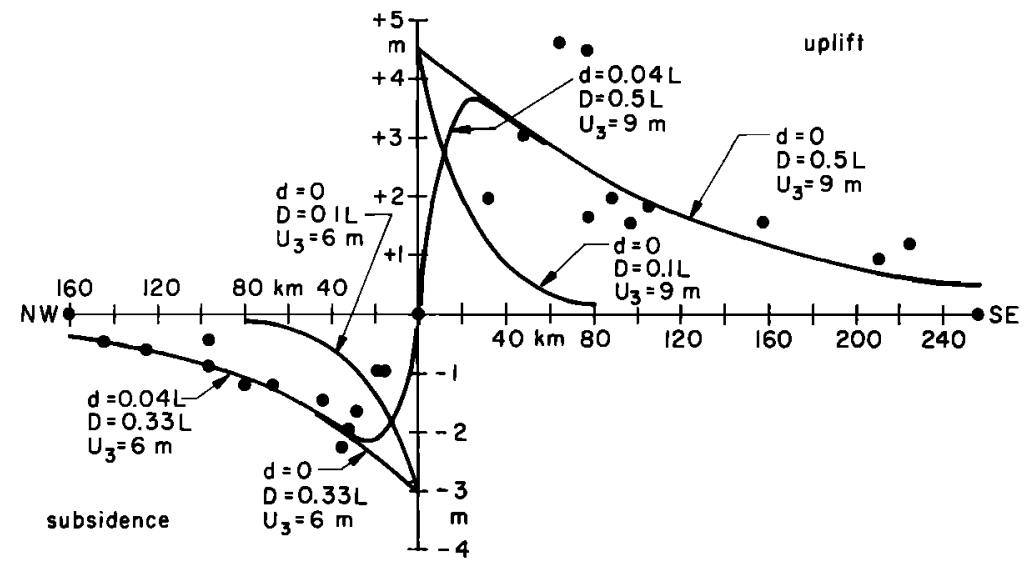

Fig. 11. Vertical movements associated with Alaskan earthquake projected on a section normal to belt of epicenters. Theoretical curves for different fault parameters are also shown. 
the fault. Thus observations at distances smaller than $30 \mathrm{~km}$ are indicative of depth to the upper boundary of the fault, whereas data at larger distances are sensitive to the depth of the lower boundary.

The asymmetry in the data relative to the hingeline is probably due to dip of the fault plane, which was neglected in the theory. The simple procedure is used of interpreting displacements for both blocks separately. We conclude on the basis of the very gradual reduction of vertical deformation with distances that the fault could not have extended to depths as shallow as $50 \mathrm{~km}$ and that 100 to $200 \mathrm{~km}$ are more likely values. The fault probably came to within 15 to $20 \mathrm{~km}$ of the surface.

As a check, we note that the contours of field observations of vertical displacement lie roughly parallel to the strike of the fault, indicating a negligible contribution from the strike-slip component of faulting. This implies that $U_{2} / U_{\mathrm{s}} \ll 1$ or that $D / L \gg 0.1$. The first possibility seems to be ruled out by the preliminary geodetic indications of horizontal slip.

The vertical extent found for the fault of the Alaskan earthquake exceeds by an order of magnitude the values found for other earthquakes. Chinnery gives 2 to $6 \mathrm{~km}$ for the San Francisco earthquake of 1906. Knopoff [1958] gives $3 \mathrm{~km}$, and Byerly and DeNoyer [1958] found a depth of $10 \mathrm{~km}$. The last-named authors also found depths of 12 and $23 \mathrm{~km}$ for the Imperial Valley (1940) and the Fairview Peak earthquakes. Kasahara and Chinnery found depths between 10 and $15 \mathrm{~km}$ for the Tango and North Idu earthquakes in Japan. The larger magnitude associated with the Alaskan earthquake ( $M=8.4)$ as compared with the others may partially explain the difference. In the case of the San Francisco earthquake, most of the displacement observations were within 5 $\mathrm{km}$ of the fault. Anomalously low rigidities in the fault zone could result in a misleading displacement-distance relationship [Benioff, 1962].

An estimate of the elastic strain energy released by the Alaskan earthquake can be made by evaluating the volume integral

$$
\int_{0}\left[\lambda \varphi^{2} / 2+\mu \sum_{i, 2=1}^{3} e_{i,} e_{i,}\right] d v
$$

where $e_{i j}$ are the strain components, $\varphi$ is the dilatation, and $\mu=5 \times 10^{11}$ dynes $/ \mathrm{cm}^{2}$. Using the fault parameters described earlier, and assuming that to a depth $D$ the strains may be approximated by the surface values and are zero below, we obtain $10^{25} \mathrm{ergs}$, with the dip-slip component contributing about twice as much as the strike-slip component. Presumably this is an upper bound for the seismic wave energy radiated from the epicentral region. A more precise calculation is being undertaken in which the exact depth dependence of strain is taken into account.

The strain energy can also be obtained from $\frac{1}{2} \iint_{\Sigma} U_{i} \tau_{i j} v_{j} d \Sigma$ where $\tau_{i j}$ are the stress components, $\Sigma$ is the surface area of the fault, and the integral represents the energy required to produce the dislocation sheet. Approximate integration yields similar results. Assuming that an earthquake could be modeled by the formation of a crack in a material in a state of uniform strain, Knopoff [1958] derived a formula for energy release $E=\pi \mu U_{1}^{2} L / 8=2 \times 10^{24}$ ergs using the preceding values for the fault parameters. This is almost identical to our result for the $U_{1}$ component of slip. The elastic strain energy release may be compared to the seismic wave energy derived from the Gutenberg-Richter relation $\log E=11.8+1.5 M$. Using $M=8.4$ yields a value of $3 \times 10^{24} \mathrm{ergs}$.

A remarkable strain seismogram was written for this earthquake at the Kipapa station on Oahu, Hawaii (latitude $21^{\circ} 25^{\prime} \mathrm{N}$, longitude $158^{\circ} 54^{\prime} \mathrm{W}$, orientation $\left.\mathrm{N} 61^{\circ} \mathrm{W}\right)$. This instrument was recently installed by the California Institute of Technology and is operated by the U. S. Coast and Geodetic Survey. It incorporates both photo-optical and electronic transducers [Blayney and Gilman, 1965]. The seismogram is displayed in Figure 12 in such a way that the strain record for several days before and after the earthquake is shown. It is seen that the strain discontinuity of $10^{-8}$ associated with the shock is a unique feature. Subsequent tests in which large strains were induced artificially failed to show a permanent strain offset, minimizing the possibility that the Alaskan strain offset was due to an instrumental defect. Perhaps the best indication as to the reality of the observation is that it is reasonably consistent with the fault model, the fault dimensions, and the slips discussed earlier.

The Hawaiian strain seismograph is located at approximate coordinates $-8 \geq x_{1} / L \geq-11$, 

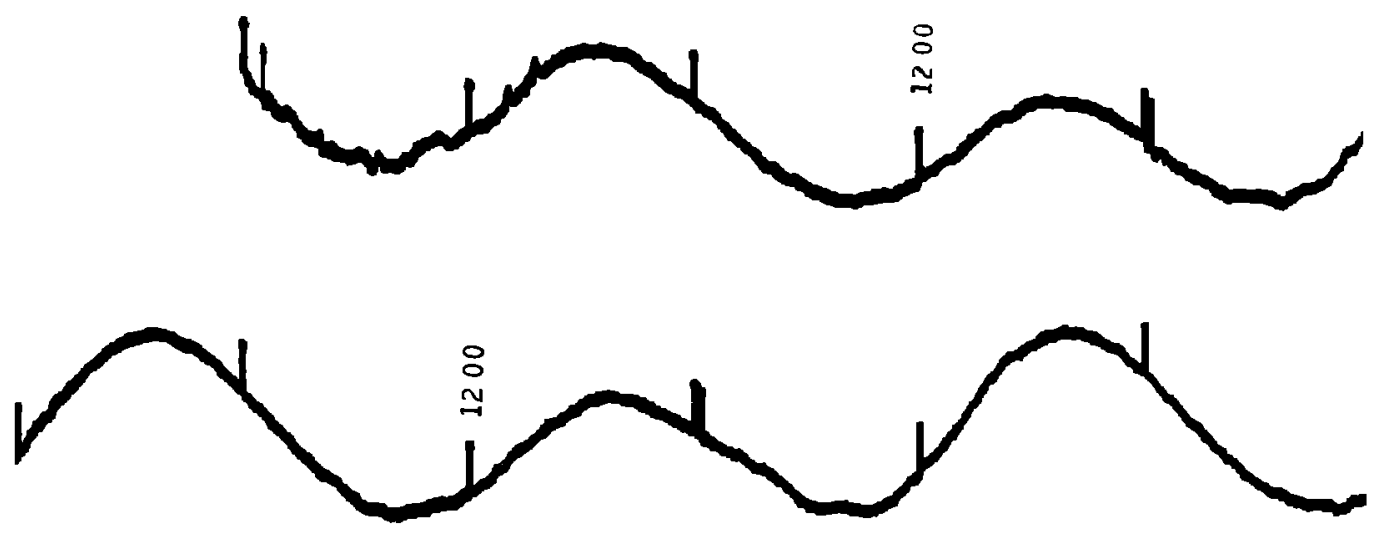

Kipapo, Howaii Strain

Alaskan Earthquake March 27, 1964

$\rightarrow 6$ hours
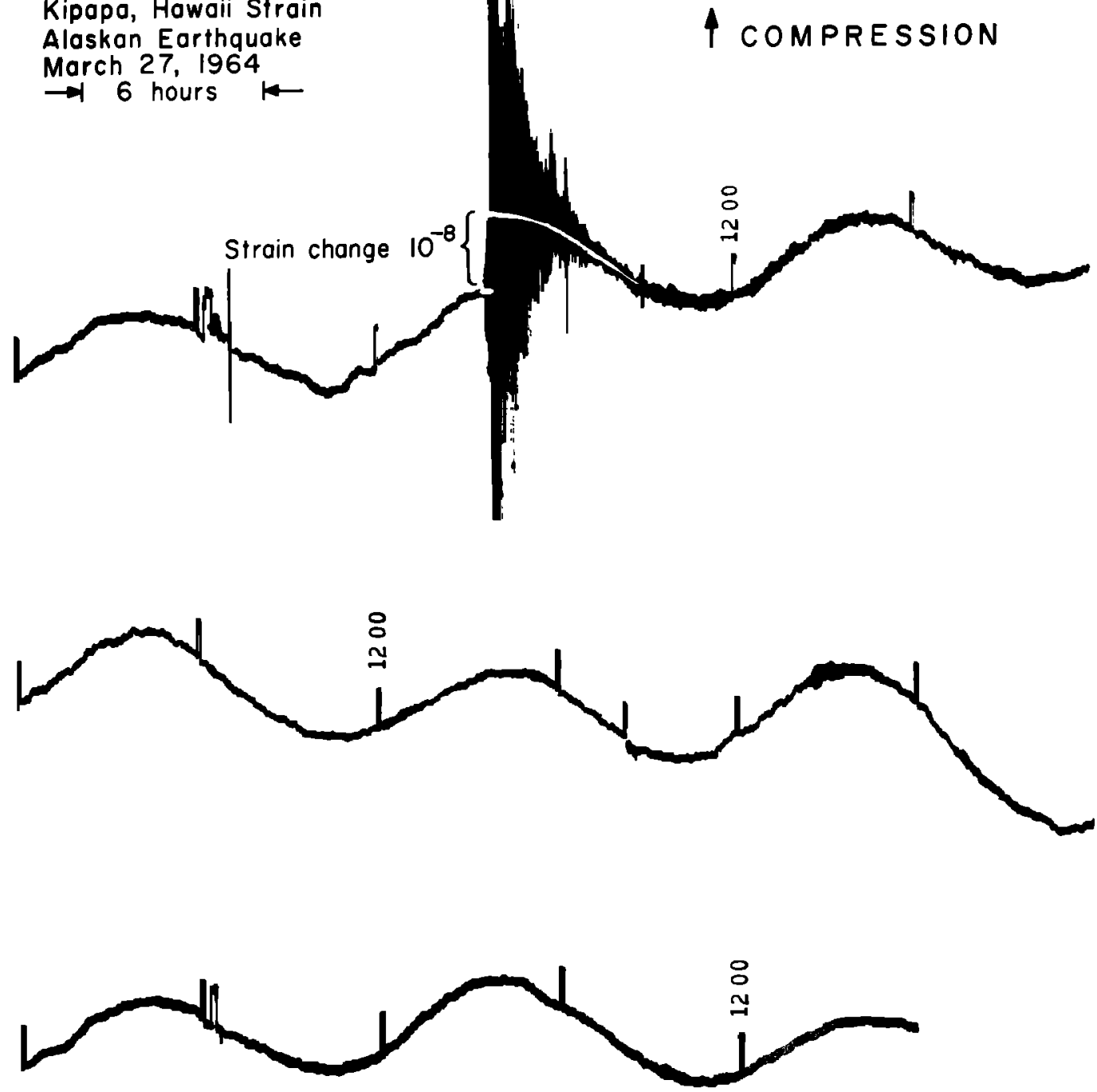

Fig. 12. Strain seismogram written at Kipapa, Oahu, for Alaskan earthquake of March 27, 1964. Several days of recording before and after the shock are shown to indicate uniqueness of residual strain. 
$3 \leq x_{2} / L \leq 5$, depending on the fault length and orientation. Since the $U_{3}$ and $U_{1}$ values for the Alaskan shock are smaller by factors of about 2 or 3 than the values assumed in computing strains in Figures 5 to 8 , we must reduce dip-slip and strike-slip strains by these amounts (also $U_{3}$ observed differs in sign from the value assumed in the figures). We note that strains of the order of $10^{-10}$ to $10^{-9}$ are present near Hawaii for $D=0.1 L$ and strains in the range $10^{-8}$ to $10^{-8}$ occur for the case $D=1.0 L$. These may be compared with the observed value of $10^{-8}$. Actually, the comparison should be made with the total strain response of the instrument in which all the theoretical strain components are added, taking account of the orientation of the strain rod and the sign of the strain components. Unfortunately, the strain rod is oriented at right angles to the extension of the fault to within $\pm 5^{\circ}$, and Hawaii falls near nodal lines of several strain fields. Small changes in the length and orientation of the fault lead to order of magnitude changes in the computed total strain response. For reasonable values of the fault parameters we find that the strike-slip component of $\partial u_{2} / \partial x_{2}$ contributes most of the strain. When $D=0.1 L$ the theoretical strain response is less than observed by several orders of magnitude, whereas $D=1.0 L$ yields a strain response of the right sign (compression) and within about an order of magnitude of that observed.

This indication of great depth of faulting substantiates the results from the near displacement fields, although it cannot carry as much weight since it is based on only one point in the strain field. The main contribution of this observation and the computation of theoretical values is the demonstration that strain observations from major earthquakes are observable at teleseismic distances and that they are diagnostic of source properties.

We have also examined the Isabella (California) strain seismograms for permanent deformation after the Alaskan earthquake. Although the records were not as convenient to read as those from Hawaii, we concluded that residual strain changes were smaller than the detection threshold of $5 \times 10^{-9}$ (zero strain change being consistent with the data). In terms of fault coordinates Isabella is located at $0 \leq x_{1} / L \leq 2$ and $x_{2} / L \sim 9$. Here again we have the unfortunate situation that the station is located near a nodal line for several strain components and that the instruments are oriented within about $10^{\circ}$ to $20^{\circ}$ of the cardinal directions defined by the fault axes. Thus small changes in fault parameters can change both the sign and order of magnitude of the strain response to the extent that the observation cannot be considered inconsistent with the Hawaiian data or the fault model.

Other observations of residual fields. Berckhemer and Schneider [1964] attempted to recover the true ground motion by integrating the trace motion of horizontal seismographs for several local earthquakes in the magnitude $4 \frac{1}{2}$ to 5 range. They found residual displacements of the order of 5 to $10 \mu$ at distances of about 60 $\mathrm{km}$. Using the fault models described earlier, we can expect such displacements at this distance for faults about $1 \mathrm{~km}$ long and slips of about $5 \mathrm{~cm}$ (nuclear explosions with this equivalent magnitude produce residual movements of this order at about $1 \mathrm{~km}$ ). These investigators also reported residual tilts of the order of $10^{-7}$. These are three to four orders of magnitude too large for the above source. Mechanical hysteresis in the pendulum would be manifest as residual tilts and this possibility should be investigated.

Another example of a residual strain observation is shown in Figure 13, where two direct strain recordings for a local earthquake near Naña, Peru, are displayed. Unfortunately, the magnitude and distance of this event are not available. Note that on mechanically and electrically identical instruments one component shows a residual strain and the perpendicular component does not. This observation supports the notion that the strain offset is real and not due to an instrumental defect.

Several measurements of strains and tilts from earthquakes have been reported which are too large by several orders of magnitude to be explained by the fault mechanism assumed earlier. In the case of the strain instruments which have been tested for instrumental hysteresis and checked by the photo-optical transducer, we feel warranted in ascribing the strain changes to the source. The tilt observations could be real, but the possibility of spurious tilts due to mechanical hysteresis in the pendulums must be checked before their validity is taken seriously. Some examples follow. 


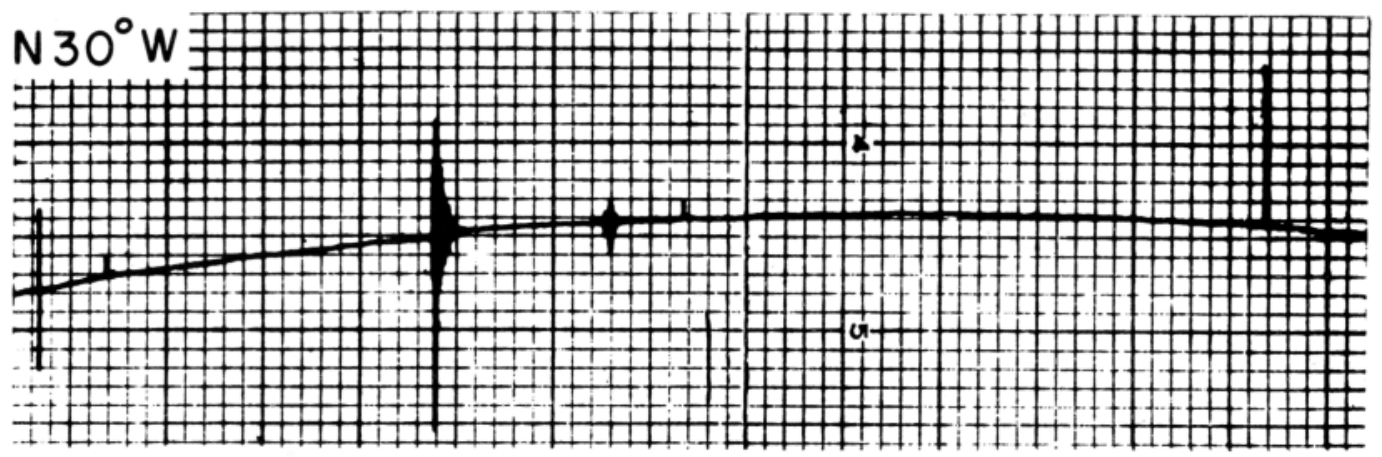

\section{Ñaña, Peru $08^{\mathrm{h}} 34^{\mathrm{m}}$ E.S.T. Dec. 12,1961}

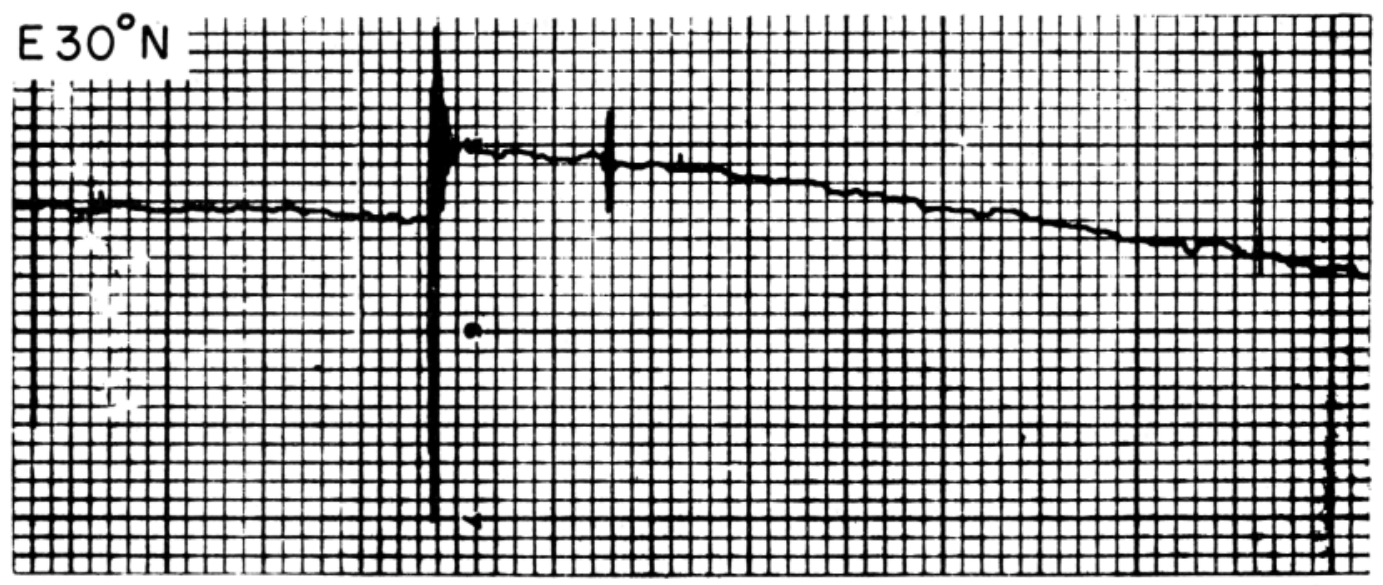

Fig. 13. Direct strain recordings at Naña, Peru, with only one component showing a residual strain after a local earthquake.

Benioff [1963] published a direct strain seismogram from Isabella for the Montana earthquake of August 19, 1959, showing a strain change of $5 \times 10^{-0}$. The primary deformation in the epicentral region was subsidence, the earthquake resulting from a sudden collapse over a broad area. Although extensive faulting accompanied the earthquake over a length of some $30 \mathrm{~km}$, with scarps as high as $6 \mathrm{~m}$, both sides of the faults moved downward [Witkind et al., 1962]. Meyers and Hamilton interpret the field data to indicate that the faults are secondary features, the primary tectonic action being basin collapse. Witkind and Fraser view the faults as primary features and believe that movements along the faults caused the earthquake. Taking $2 L=30 \mathrm{~km}$ and $290^{\circ}$ for the azimuth of the strike of the fault, we get for the coordinates of Isabella $x_{1} / L \sim 20, x_{2} / L \sim 75$. Using $U_{3}=3 \mathrm{~m}$ for the average slip and $D / L=$
1.0 for the vertical extent of faulting, we find strain components in the range $10^{-12}$ to $10^{-11}$ at Isabella, values which are two to three orders of magnitude smaller than observed. We conclude that more extensive faulting occurs at depth than is manifest at the surface or that a nonfaulting mechanism is responsible for subsidence in the epicentral region and the residual strain at Isabella. The possibility that volume changes at depth can account for these changes is now being examined.

Figure 14 is a direct strain seismogram written at Kipapa, Oahu, from the earthquake of October 11, 1964, off the west coast of Hawaii. This tremor had a magnitude of about 5 . The strain change at Kipapa of $4 \times 10^{-9}$ was measured with both the electronic and photo-optical transducers, as shown in the figure. An earthquake of magnitude 5 , having a faulting mechanism, may be expected to have a fault length 


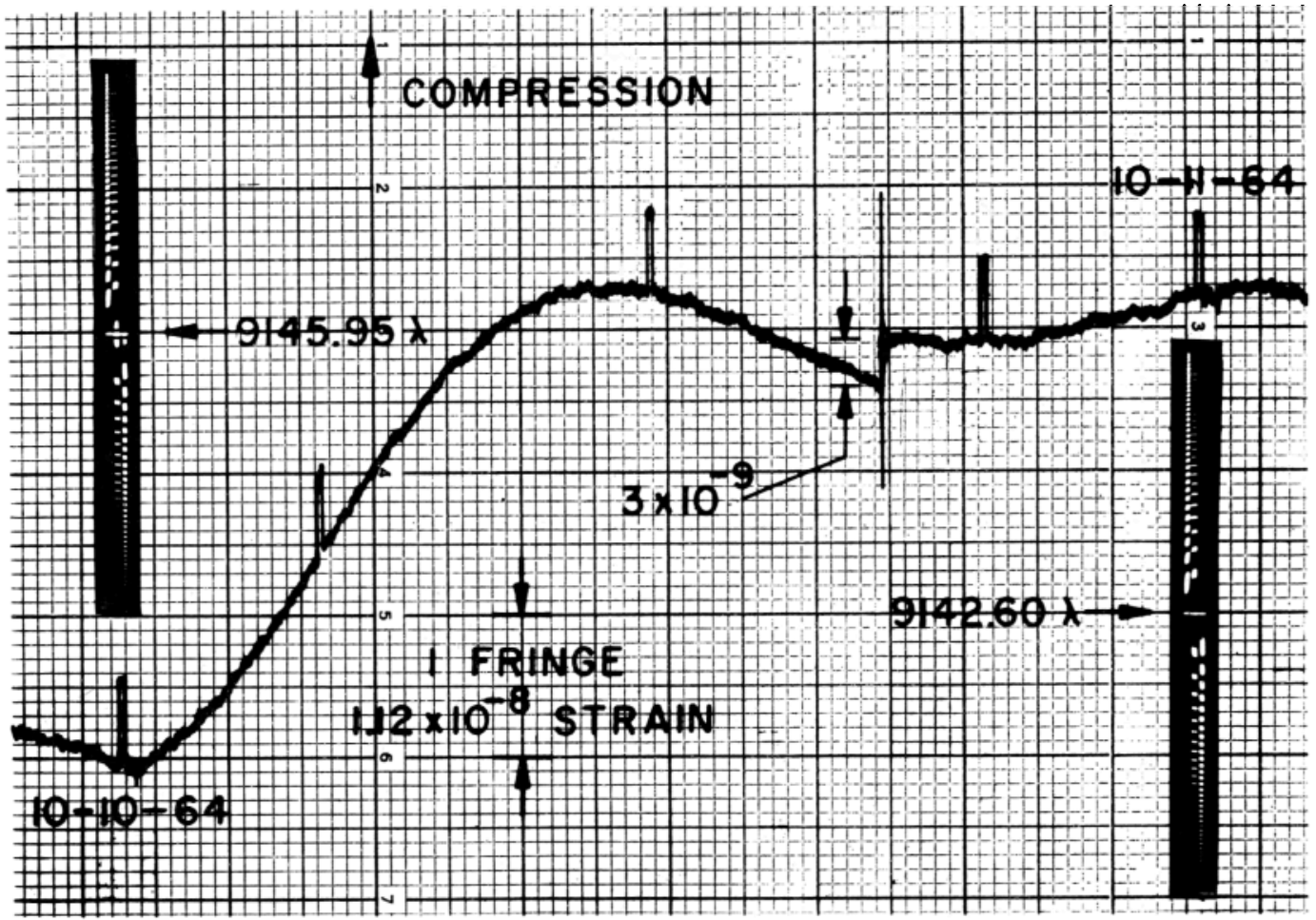

Fig. 14. Direct strain recording at Kipapa, Oahu, for Hawaiian earthquake of October 11, 1964. Fringe pattern indicates separation of interferometer plates in wavelengths of mercury green line in agreement with trace motion derived from electronic transducer.

of well under $5 \mathrm{~km}$. In terms of this length, Kipapa falls at a distance larger than $100 \mathrm{~L}$ from the source. For a slip of $0.3 \times 10^{-4} \mathrm{~L}$ and vertical fault extent $D=1.0 \mathrm{~L}$ the strains are at least three orders of magnitude smaller than the observed value. We conclude that the source mechanism did not involve strain release from primary tectonic faulting of the type assumed in this paper. The result is not surprising since it is well known that earthquakes and deformation on Hawaii are associated with volcanism rather than tectonic faulting [Eaton and $\mathrm{Mu}$ rata, 1960].

Residual tilts connected with large teleseismic events have been reported by Bonchkovsky [1962], Nishimura [1953], and Tomaschek [1955]. Bonchkovsky studied tilts at Garm and Simferopol from the great Mongolian earthquake of December 4,1957 . He reported tilts of $10^{-5}$ and $\frac{1}{2} \times 10^{-5}$ for the two stations. The main fracture for this earthquake could be traced over a distance of $270 \mathrm{~km}$. Aftershocks occurred in a belt $500 \mathrm{~km}$ long, and instrumen- tal determination of fault length gave $560 \mathrm{~km}$ [Ben-Menahem and Toksöz, 1962]. Strike-slip movements of 3 to $3.5 \mathrm{~m}$ and dip-slips as much as $8 \mathrm{~m}$ were found at places along the fault. We represent the fault by the following approximate parameters. $2 L=500 \mathrm{~km}, U_{1}=3$ $\mathrm{m}, U_{\mathrm{s}}=6 \mathrm{~m}$. Using the reported orientation of the fault, we find that the coordinates of Garm are $x_{1} / L \sim 10, x_{2} / L \sim 2.5$ and the Simferopol coordinates are $x_{1} / L \sim 18, x_{2} / L \sim 7$. The theoretical tilts at these locations are of the order of $10^{-8}$ to $10^{-9}$, or three to four orders of magnitude smaller than observed. The elastic strain energy change required to produce tilts of the order of those observed at these distances is impossibly high. The residual tilts reported by Tomaschek can also be shown to be too large. A discussion of the origin of these tilts is unwarranted until the instruments are tested for mechanical hysteresis induced by large-amplitude seismic waves.

Discussion. The previous discussion should be viewed primarily as a feasibility study in which 
an approximate theory and some single point observations show the possibilities of a more extensive experiment.

The use of residual displacements, strains, and tilts at intermediate and large distances from the epicenter offers new opportunities for studying the mechanism of earthquakes. The dimensions of the source, the elastic strain energy release, and the elucidation of primary mechanisms other than faulting ones are among the problems which may be studied by this approach. It is technically feasible to develop and deploy instruments to monitor the residual fields for an entire seismic belt. Without the former necessity for limiting observations to the epicentral region, data can be gathered in a relatively short period of time. Moreover, the installation of displacement-, strain-, and tiltmeters in arrays having continental dimensions offers the possibility of using correlation methods to improve signal-to-noise ratios so that residual fields from smaller events can be studied. Such an array might also monitor slowly varying fields or the more rapid variations associated with creep instability before an earthquake occurs.

Theoretical advances will be needed to exploit these observations fully. The dislocation theory representation of faults should be extended to include fault planes of arbitrary slip and orientation in a layered, spherical earth. Fields due to density changes over arbitrary regions should be programmed for computation. Methods will be needed to compute fields from realistic sources in which the mechanism of failure and the pre-existing strain field are taken into account.

Acknowledgments. I have benefited from many discussions with Drs. Stewart Smith, Hugo Benioff, Ari Ben-Menahem, and Don Anderson. Dr. Shawn Biehler generously adapted his automatic plotting routine for use in this paper. Dr. Keiiti Aki and Mr. George Plafker made their studies of the Alaskan earthquake available in advance of publication. Messrs. Ronald Viets, Robert Eppley, and Robert Munson of the U. S. Coast and Geodetic Survey station at Kipapa provided valuable assistance in operating the strain seismograph for us. Lawrence Turnbull checked the calculations.

I am grateful to Drs. Hugo Benioff, M. A. Chinnery, $K$. Aki, and M. Major for constructive comments on the paper. Dr. Aki mentioned a study which I have not yet seen by Dr. I. Ozawa of Kyoto University in which a similar conclusion about the reality of strain jumps is reached.
This work was partially supported by the $\mathrm{Na}$ tional Science Foundation under grant GP-2806.

\section{REFERENCES}

Aki, K., Study of Love and Rayleigh waves from earthquakes with fault plane solutions or with known faulting, Bull. Seismol. Soc. Am., 54, 511$570,1964$.

Algermissen, S. T., Prince William Sound, Alaska earthquake of March 28, 1964, and aftershock sequence (abstract), Program 1964 Ann. Meeting Geol. Soc. Am., p. 2, 1964.

Archambeau, C., Elastodynamic source theory, Ph.D. thesis, California Institute of Technology, June 1964.

Benioff, H., Movements on major transcurrent faults, in Continental Drift, edited by S. K. Runcorn, pp. 103-134, Academic Press, New York, 1962.

Benioff, H., Source wave forms of three earthquakes, Bull. Seismol. Soc. Am., 58, 893-903, 1963.

Ben-Menahem, A., and M. N. Toksöz, Sourcemechanism from spectra of long-period seismic surface-waves, J. Geophys. Res., 67, 1943-1955, 1962.

Ben-Menahem, A., and M. N. Toksöz, Sourcemechanism from spectra of long-period seismic surface waves, Bull. Seismol. Soc. Am., 58, 905919, 1963.

Berckhemer, H., and G. Schneider, Near earthquakes recorded with long-period seismographs, Bull. Geol. Soc. Am., 54, 973-987, 1964.

Blayney, J. L., and R. Gilman, A semi-portable strain meter with continuous interferometric calibration, to be submitted for publication in 1965.

Bonchkovsky, V. F., Deformation of the earth's surface accompanying certain disastrous earthquakes, Bull. Acad. Sci. USSR, Geophys. Ser., English Transl., 2, 190-193, 1962.

Brune, J. N., Correction of initial phase measurements for the southeast Alaska earthquake of December 4, 1957, J. Geophys. Res., 67, 3643, 1962.

Byerly, P., and J. DeNoyer, Energy in earthquakes as computed from geodetic observations, Contributions in Geophysics, vol. 1, pp. 17-35, Pergamon Press, London, 1958.

Chinnery, M. A., The deformation of the ground around surface faults, Bull. Seismol. Soc. Am., 61, 355-372, 1961.

Chinnery, M. A., The stress changes that accompany strike-slip faulting, Bull. Seismol. Soc. Am. $58,921-932,1963$.

Eaton, J. P., and K. J. Murata, How volcanoes grow, Science, 192, 925-938, 1960.

Grantz, A., G. Plafker, and J. E. Case, Tectonics of Alaska's Good Friday earthquake (abstract), Program 1964 Ann. Meeting, Geol. Soc. Am., p. 77, 1964a.

Grantz, A., G. Plafker, and R. Kachadoorian, Alaska's Good Friday earthquake, March 27, 1964, U. S. Geol. Surv. Citc. 491, $1964 b$. 
Kasahara, K., The nature of seismic origins as inferred from seismological and geodetic observations, Bull. Earthquake Res. Inst., Tokyo Univ., 35, 473-532, 1957.

Knopoff, L., Energy release in earthquakes, Geophys. J., 1, 44-52, 1958.

Malloy, R. J., Crustal uplift southwest of Montague Island, Alaska, Science, 146, 1048-1049, 1964.

Maruyama, T., Statical elastic dislocations in an infinite and semi-infinite medium, Bull. Earthquake Res. Inst., Tokyo Univ., 42, 289-368, 1964.

Mindlin, R. D., and D. H. Cheng, Nuclei of strain in the semi-infinite solid, J.Appl. Phys., 21, 926930, 1950.

Nishimura, E., On some destructive earthquakes observed with a tiltmeter at a great distance, Bull. Disaster Prevention Res. Inst., Kyoto Univ., 6, 1-16, 1953.

Plafker, G., Tectonic uplift, subsidence, and faulting associated with Alaska's Good Friday earthquake, Science, in press, 1965.

Press, F, and C. Archambeau, Release of tectonic strain by underground nuclear explosions, $J$. Geophys. Res., 6\%, 337-343, 1962.

Steketee, J. A., On Volterra's dislocations in a semi-infinite medium, Can. J. Phys., 36, 192-205, 1958.

Tomaschek, R., Earth tilts in the British Isles connected with far distant earthquakes, Nature, $176,24-26,1955$.

Vvedenskaya, A. V., The determination of displacement fields by means of dislocation theory, Bull. Acad. Sci. USSR, Geophys. Ser., English Transl., 3, 277-284, 1956.

Whitten, C. A., Cartographic and geodetic effects of Alaskan earthquake (abstract), Program 1964 Ann. Meeting, Geol. Soc. Am., p. 222, 1964.

Witkind, I. J., W. B. Meyers, J. B. Hadley, W. Hamilton, and G. D. Fraser, The earthquake at Hebgen Lake, Montana, on August 18, 1959: Geological features, Bull. Seismol. Soc. Am., 62, 163-180, 1962.

(Manuscript received January 21, 1965; revised March 5, 1965.) 